\section{Category}

Synthesis of

Materials and

Unnatural Products

\section{Key words}

\section{C-H activation}

rhenium catalysis

intramolecular nucleophilic cyclization

polyimides

S. SUEKI, Y. GUO, M. KANAI, Y. KUNINOBU* (THE UNIVERSITY OF TOKYO AND CREST SCIENCE AND TECHNOLOGY AGENCY, TOKYO, JAPAN)

Rhenium-Catalyzed Synthesis of 3-Imino-1-isoindolinones by C-H Bond Activation: Application to the Synthesis of Polyimide Derivatives

Angew. Chem. Int. Ed 2013, 52, 11879-11883.

\title{
Insert, Cyclize, Eliminate: Polyimides from Imidates and Isocyanates
}

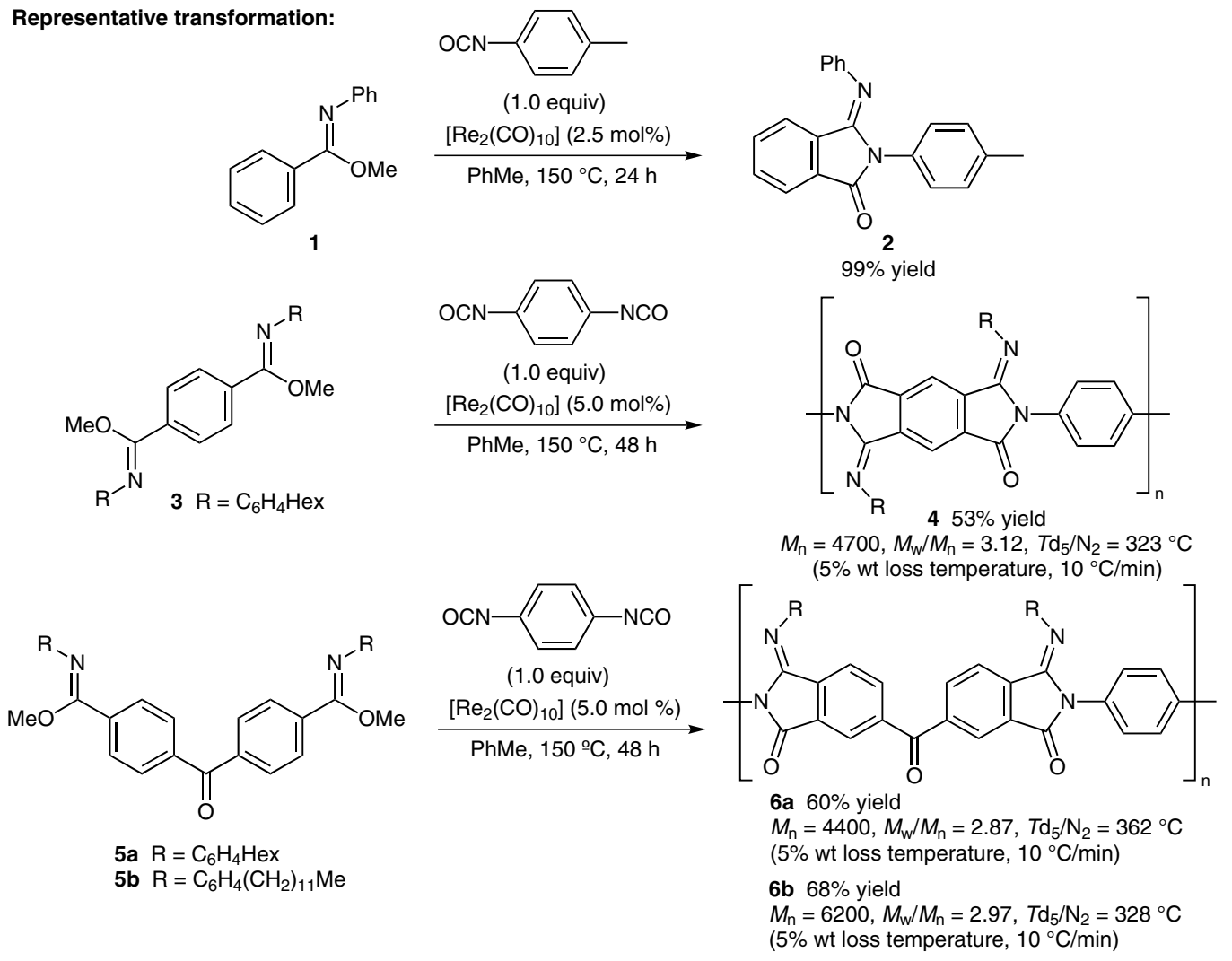

Significance: Polyimides find application in aerospace engineering and electronic materials because of their inherent rigidity, strength, heatresistance, and electrical non-conductance. However, their low solubility in organic solvents limits processability. The authors hypothesized that the solubility could be improved by switching the carbonyl group into an imino group functionalized with pendant alkyl chains. They confirmed their hypothesis by developing a mild, atom-economical rhenium-catalyzed transformation that involves sequential $\mathrm{C}-\mathrm{H}$ activation, intramolecular nucleophilic cyclization, and elimination of methanol.

SYNFACTS Contributors: Timothy M. Swager, Joseph. M. Azzarelli Synfacts 2014, 10(1), 0034 Published online: Dol: 10.1055/s-0033-1340389; Reg-No.: S14513SF
Comment: The key step in the reported methodology is the restoration of the $\mathrm{C}=\mathrm{N}$ double bond by elimination of a small molecule (methanol). The efficacy of this tactic is evidenced by the good yields obtained throughout a diverse substrate scope and on a gram-scale reaction ( $80 \%$ yield). This is the first example of polyimide derivatives having imino groups; the polymers obtained are highly soluble in toluene, tetrahydrofuran, dichloromethane, and chloroform. It will be important to explore the mechanical properties of this new class of polyimides to determine how they compare to their less soluble, carbonyl-containing counterparts. 